\title{
ERRATUM
}

\section{Associations among anthropometric measures, food consumption, and quality of life in school-age children in Tanzania}

Mayumi Ohnishi, Sebalada Leshabari, Joel Seme Ambikile, Kazuyo Oishi,

Yuko Nakao and Mika Nishihara

Vol. 12, No. 1 (2017), p. 41, Table 4 should have been as follows;

P-value of "Living with parent(s)" -- The differences were determined by ANOVA.

Table 4 Sociodemographic characteristics, Rohrer index score, and QOL score of the study participants $(n=694)$

\begin{tabular}{|c|c|c|c|c|c|c|c|c|c|c|c|}
\hline & \multirow{3}{*}{$n$} & \multirow{3}{*}{$\%$} & \multicolumn{6}{|c|}{ Rohrer index score } & \multirow{3}{*}{$\begin{array}{c}P \text {-value } \\
\text { (Chi-square } \\
\text { test) }\end{array}$} & \multirow{3}{*}{$\begin{array}{l}\text { QOL score } \\
\text { Mean } \pm \text { SD }\end{array}$} & \multirow{3}{*}{$\begin{array}{l}P \text {-value } \\
(t \text { test })\end{array}$} \\
\hline & & & \multicolumn{2}{|c|}{$\begin{array}{l}\text { Low weight } \\
(n=273)\end{array}$} & \multicolumn{2}{|c|}{$\begin{array}{l}\text { Normal weight } \\
\qquad(n=353)\end{array}$} & \multicolumn{2}{|c|}{$\begin{array}{l}\text { Overweight } \\
\quad(n=68)\end{array}$} & & & \\
\hline & & & $\mathrm{n}$ & $\%$ & $\mathrm{n}$ & $\%$ & $\mathrm{n}$ & $\%$ & & & \\
\hline \multicolumn{12}{|l|}{ Region } \\
\hline Dar es Salaam & 476 & 68.6 & 191 & 40.1 & 231 & 48.7 & 53 & 11.1 & 0.114 & $23.5 \pm 3.8$ & 0.001 \\
\hline Moshi & 218 & 31.4 & 82 & 37.6 & 121 & 55.5 & 15 & 6.9 & & $24.5 \pm 3.6$ & \\
\hline \multicolumn{12}{|l|}{ Location } \\
\hline Urban & 318 & 45.8 & 133 & 41.8 & 153 & 48.1 & 32 & 10.1 & 0.399 & $23.9 \pm 3.3$ & 0.065 \\
\hline Rural & 376 & 54.2 & 140 & 37.2 & 200 & 53.2 & 36 & 9.6 & & $23.8 \pm 4.1$ & \\
\hline \multicolumn{12}{|l|}{ Gender } \\
\hline Male & 312 & 45.0 & 137 & 43.9 & 162 & 51.9 & 13 & 4.2 & $<0.001$ & $24.2 \pm 3.3$ & 0.057 \\
\hline Female & 382 & 55.0 & 136 & 35.6 & 191 & 50.0 & 55 & 14.4 & & $23.6 \pm 4.0$ & \\
\hline \multicolumn{12}{|l|}{ Age group } \\
\hline 10-12 years old & 502 & 72.3 & 188 & 37.5 & 268 & 53.4 & 46 & 9.2 & 0.097 & $23.9 \pm 3.8$ & 0.313 \\
\hline$\geq 13$ years old & 192 & 27.7 & 85 & 44.3 & 85 & 44.3 & 22 & 11.5 & & $23.6 \pm 3.6$ & \\
\hline \multicolumn{12}{|l|}{ Living with parent(s) } \\
\hline Living without parents & 115 & 16.6 & 41 & 35.7 & 62 & 53.9 & 12 & 10.4 & 0.691 & $23.2 \pm 4.5$ & $0.112^{\mathrm{a}}$ \\
\hline Living with one parent & 203 & 29.3 & 86 & 42.4 & 101 & 49.8 & 16 & 7.9 & & $23.8 \pm 3.7$ & \\
\hline Living with parents & 376 & 54.2 & 146 & 38.8 & 190 & 50.5 & 40 & 10.6 & & $24.1 \pm 3.5$ & \\
\hline \multicolumn{12}{|l|}{ Working status } \\
\hline Not working & 645 & 92.9 & 253 & 39.2 & 329 & 51.0 & 63 & 9.8 & 0.943 & $23.9 \pm 3.7$ & 0.150 \\
\hline Working & 44 & 6.3 & 17 & 38.6 & 22 & 50.0 & 5 & 11.4 & & $23.1 \pm 3.8$ & \\
\hline \multicolumn{12}{|c|}{ Number of meals on the day before the survey } \\
\hline$\leq 2$ & 235 & 33.9 & 84 & 35.7 & 124 & 52.8 & 27 & 11.5 & 0.293 & $22.6 \pm 4.1$ & $<0.001$ \\
\hline$\geq 3$ & 459 & 66.1 & 189 & 41.2 & 229 & 49.9 & 41 & 8.9 & & $24.5 \pm 3.4$ & \\
\hline \multicolumn{12}{|c|}{ Consumption of protein-rich food on the day before the survey } \\
\hline No & 127 & 18.3 & 50 & 39.4 & 62 & 48.8 & 15 & 11.8 & 0.680 & $23.1 \pm 4.0$ & 0.014 \\
\hline Yes (at least once) & 567 & 81.7 & 223 & 39.3 & 291 & 51.3 & 53 & 9.3 & & $24.0 \pm 3.7$ & \\
\hline
\end{tabular}

${ }^{\mathrm{a}}$ ANOVA. 